\title{
BMJ Open Adaptation and validation of the Physical Activity Questionnaire for Adolescents (PAQ-A) among Polish adolescents: cross-sectional study
}

\author{
Justyna Wyszyńska (D , , ${ }^{1}$ Piotr Matłosz, ${ }^{2}$ Justyna Podgórska-Bednarz, ${ }^{1}$ \\ Jarosław Herbert, ${ }^{2}$ Krzysztof Przednowek (D) , ${ }^{2}$ Joanna Baran, ${ }^{1}$ Katarzyna Dereń, ${ }^{1}$ \\ Artur Mazur ${ }^{3}$
}

To cite: Wyszyńska J, Matłosz P Podgórska-Bednarz J, et al. Adaptation and validation of the Physical Activity Questionnaire for Adolescents (PAQ-A) among Polish adolescents: crosssectional study. BMJ Open 2019;9:e030567. doi:10.1136/ bmjopen-2019-030567

- Prepublication history and additional material for this paper are available online. To view these files, please visit the journal online (http://dx.doi org/10.1136/bmjopen-2019030567).

Received 20 March 2019 Revised 20 September 2019 Accepted 28 0ctober 2019

Check for updates

(C) Author(s) (or their employer(s)) 2019. Re-use permitted under CC BY-NC. No commercial re-use. See rights and permissions. Published by BMJ.

${ }^{1}$ Institute of Health Sciences, Medical College of Rzeszów University, Rzeszów University, Rzeszów, Podkarpacie, Poland ${ }^{2}$ Institute of Physical Culture Sciences, Medical College of Rzeszów University, Rzeszów University, Rzeszów, Podkarpacie, Poland

${ }^{3}$ Institute of Medical Sciences, Medical College of Rzeszów University, Rzeszów University, Rzeszów, Podkarpacie, Poland

Correspondence to Dr Justyna Wyszyńska; justyna.wyszynska@onet.pl

\section{ABSTRACT}

Objective The lack of a widely accepted questionnaire used to assess the physical activity (PA) of adolescents in the Polish language creates a need to introduce such a valid, reliable, inexpensive and quick tool for assessment. This study was designed to culturally adapt and validate the Physical Activity Questionnaires for Adolescents (PAQ-A) in the Polish language.

Design Cross-sectional study.

Participants and outcome measures Cultural adaptation of the Polish version of the PAQ-A was performed following the standardised questionnaires cultural adaptation process. In a sample of 78 adolescents aged 14-19 years, the PAQ-A test-retest was administered within a 1 -week interval. Reliability was analysed by the intraclass correlation coefficient (ICC) and internal consistency with Cronbach's $\alpha$. Participants completed the PAQ-A, and wore an accelerometer for 7 consecutive days. The PAQ-A was compared with PA parameters obtained using the accelerometer.

Results Test-retest reliability showed ICC $=0.97$ for the total score of PAQ-A. Internal consistency was excellent $(\alpha=0.93)$. The PAQ-A was very strongly correlated with steps per day $(r=0.94)$ and with moderate-to-vigorous PA $(r=0.81)$ assessed by the accelerometer.

Conclusions The Polish version of the PAQ-A is a valuable tool to estimate general levels of PA among adolescents from 14 to 19 years old.

\section{INTRODUCTION}

One of the most important factors determining human health is physical activity (PA), which is defined as body movement resulting from skeletal muscle contraction during which energy expenditure is increased. ${ }^{1}$ Physical inactivity is responsible for about 3.2 million deaths per year, being one of the most important risk factors for non-communicable diseases such as coronary heart disease, type 2 diabetes and cancer. ${ }^{2}$ According to the WHO, more than $80 \%$ of the world's adolescent population is insufficiently physically active. ${ }^{3}$ Increasing evidence
Strengths and limitations of this study

- This study provides the first Physical Activity Questionnaire for Adolescents (PAQ-A) cultural adaptation and validation study among Polish adolescents aged 14-19 years.

- The Polish version of the PAQ-A was compared with a device-based measure of physical activity (triaxial accelerometry) to determine the validity of the questionnaire.

- In this study, we used international standards for validating the questionnaire.

- Limitations of this study are the small sample size and the relatively high dropout rate of participants due to accelerometer non-wear periods.

suggests that declining PA is a major factor for higher prevalence of childhood obesity. ${ }^{4}$ Worldwide, over 340 million children and adolescents aged 5-19 were overweight or obese in $2016 .{ }^{5}$ Not only PA is an important factor in the prevention of chronic diseases such as obesity, hypertension and cardiovascular diseases, ${ }^{6}$ but also there is evidence that regular participation in PA has a positive impact on psychosocial well-being, cognitive outcomes and mental health. ${ }^{7}$ Accurate measurement of PA is important to understand the association between PA and health, monitor changes in PA patterns and evaluate the effectiveness of interventions.

To assess PA level, valid and reliable measures are required. The doubly labelled water method is the most widely accepted technique and the gold standard for assessing total energy expenditure; however, it is not often used for research studies as it is expensive, time-intensive and cannot capture qualitative data. ${ }^{8}$ Self-report questionnaires, despite their limitations, are often used due to their low cost and ease of administration, 
ability to measure large samples and to contextualise PA. ${ }^{9}$ Weaknesses of self-report questionnaires include, among others inaccuracies, the tendency to over-report PA levels, inability to use with young children (below the age of 10 or 11 ) and inability to compare results across studies due to the large number of measures available. ${ }^{10}{ }^{11} \mathrm{~A}$ more accurate estimate of $\mathrm{PA}$ is provided by device-based measures (such as accelerometers, pedometers, heart-rate monitors). ${ }^{11}$ An advantage of accelerometers include minuteby-minute monitoring, capturing intensity level, large memory capacities ${ }^{8}$ and feasibility with young children. ${ }^{12}$ However, accelerometers do not provide information on both the type and context of PA. Moreover, accelerometers are expensive and require technical expertise, specialised hardware, software and individual programming. ${ }^{13}$ Results of a systematic review that compared PA measures from accelerometers with PA scores of questionnaires indicated that correlations between questionnaires and accelerometry were weak to moderate. ${ }^{14}$ This finding is in agreement with previous reviews. ${ }^{15} 16$

A systematic review by Chinapaw et al which examined 61 versions of PA questionnaires for youth found that none of the questionnaires included in the review had acceptable levels of reliability and validity according to guidelines described in the Qualitative Attributes and Measurement Properties of Physical Activity Questionnaires. ${ }^{17}$ Biddle $e t$ al also reviewed available self-report PA instruments developed for children and adolescents to assess their suitability and feasibility for use in population surveillance systems and tracking trends over time, particularly in Europe. The authors identified 20 activity-based measures, of which 3 were supported by the majority of the expert group: the Physical Activity Questionnaire for Older Children and the Physical Activity Questionnaire for Adolescents (PAQ-A), Youth Risk Behaviour Surveillance Survey and the Teen Health Survey. These PA measurement instruments demonstrated both reliability and validity and also ease of use. ${ }^{9}$

The PAQ-A was developed in Canada by Kowalski et $a l .{ }^{18}$ Research results by Kowalski and others indicate that PAQ-A is a reliable, inexpensive, easy and quick tool used to assess PA in adolescents. ${ }^{18-20}$ Cultural adaptation and validation of this questionnaire has not yet been assessed in Poland. The adaptation of a tool to assess the PA of adolescents in Poland will not only allow for easy and quick large-scale research, but also enable result comparison among countries.

The main aim of this study was to assess the reliability and validity of a Polish version of the PAQ-A in adolescents.

\section{METHODS}

\section{Study design and setting}

A cross-sectional survey was conducted at four randomly selected middle and high schools in south-eastern Poland. Six classes were randomly selected from the schools representing students ranging from 14 to 19 years of age.

\section{The PAQ-A}

The PAQ-A is an eight-item, 7-day PA recall that assesses participation in various types of PA including activity during physical education, lunch break, after school, during evenings and weekends. A ninth item not used in the calculation of the activity score asks adolescents if they were sick or otherwise prevented them from engaging in regular PA. The PAQ-A was originally designed for adolescents aged 14-20. The questionnaire can be used to assess the level of PA during the school year, but not during holidays. Each item is scored according to a five-point scale (1-5), with ' 1 ' indicating low and ' 5 ' a high level of PA. The end result is the average value of the points obtained, with higher scores corresponding to a higher level of PA. ${ }^{18}$

\section{Translation and cultural adaptation of the Polish PAQ-A}

Author approval was obtained for the process of linguistic adaptation and validation of the PAQ-A questionnaire. Cultural adaptation of the Polish PAQ-A was performed following the basic steps of the standardised questionnaires cultural adaptation process. ${ }^{21}$ The original version of PAQ-A was translated into Polish by two independent translators who are fluent in English but whose native language is Polish. Then, during a meeting of both translators, both versions of the translations were compared. A final compatible version was then agreed on. It was evaluated by specialists in the field of physical education and health sciences, in terms of the unambiguity of understanding of the content included in the questions, the transparency of all items and their usefulness. The accepted version of the questionnaire was translated into English again. The back translation was made by two independent translators who had no knowledge of the original PAQ-A version, and whose native language was English (native speakers). During the meeting, both versions were compared and it was determined which one was most adequate. Then, all discrepancies between the original version and the version resulting from the back translation were carefully analysed and corrected. Subsequently, the PAQ-A was given to young people $(n=20)$ aged between 14 and 19 years in order to detect possible ambiguities in wording and to assess the understanding of the questionnaire. During this analysis, students were encouraged to consult with researchers concerning questions or statements that were unintelligible or misleading. After the appropriate corrections were made, the final Polish version of the research tool was agreed on. The Polish version of PAQ-A is presented in supplementary materials (online supplementary file 1 ).

\section{Study participants}

Prior to study commencement, we obtained written informed parent/guardian and participant consent. We invited adolescents aged 14-19 years from four randomly selected middle and high schools to participate in this study (150 informed consents were distributed). Out of this number, 122 parents/adolescents agreed to participate in the study. Of these, 44 were excluded from 
the study for the following reasons: disease or injury preventing standard PA $(n=2)$; participants without valid accelerometer measurement period $(n=23)$; the device showing a mechanical error and/or operator error $(n=7)$; incorrect anthropometry $(\mathrm{n}=1)$; refusal to participate $(n=1)$; failure to return or an incomplete survey $(n=10)$. In total, 78 students ( 38 girls and 40 boys) were included in the analysis.

\section{Patient and public involvement}

Neither patients nor public were involved in the design or planning of this study.

\section{Initial measurements}

Anthropometric measurements (body mass, body weight) were performed under standard conditions. Body height was measured in an upright position, barefoot, to the nearest $0.1 \mathrm{~cm}$ using a portable stadiometer (Seca 213). Body mass was assessed with an accuracy of $0.1 \mathrm{~kg}$ using a body composition analyser (BC-420, Tanita). Body mass index (BMI) was calculated as weight $(\mathrm{kg}) /$ height $(\mathrm{m}){ }^{2}$ Based on BMI values, the BMI percentile of individual participants were calculated. Polish BMI percentile charts specific for age, sex, and body height were used. ${ }^{22}$ Based on the BMI percentile values, underweight $(<5$ th percentile), healthy weight (between 5 th and 85 th percentile), overweight (BMI $\geq 85$ th percentile and $<95$ th percentile) or obesity ( $\geq 95$ th percentile) were determined. The definitions of underweight, healthy weight, overweight and obesity were based on the recommendations of the Centers for Disease Control and Prevention. ${ }^{23}$

\section{Accelerometry}

An ActiGraph WGT3X-BT monitor device (Pensacola, USA) was used to assess PA. ${ }^{24}$ It is a small device that provides data related to total PA including the frequency, intensity and duration. The Actigraph accelerometer has been shown to be a reliable and valid tool for the assessment of different types of PA. ${ }^{25-27}$ The accelerometer was placed at the waist with a flexible strap above the right hip bone to measure the number and frequency of participant movement. The participants were instructed to wear the accelerometer for seven consecutive days, 24 hours/ day, excluding water-based activities (baths, swimming). The ActiGraph accelerometer measures accelerations in the range of $0.05-2 \mathrm{~g}$, which is digitised by a 12 -bit analogue-to digital converter at a rate of $30 \mathrm{~Hz}$. Data was collected in $5 \mathrm{~s}$ epochs. Non-wear time was defined as $60 \mathrm{~min}$ of consecutive zeros allowing for $2 \mathrm{~min}$ of nonzero interruptions..$^{28} \mathrm{~A}$ wear time of $\geq 500 \mathrm{~min} /$ day was used as the criterion for a valid day, and $\geq 4$ days were used as the criteria for a valid 7-day period of accumulated data (including $\geq 3$ valid weekdays and $\geq 1$ valid weekend day). ${ }^{28}$ For each participant, the mean moderate-tovigorous PA (MVPA) (min/day) and the mean daily step count were calculated. The cutoff points from Evenson et al were selected to determine the time spent on MVPA level ( $\geq 2296$ counts $/ \mathrm{min}) .{ }^{29}$ MVPA time was calculated as the mean daily minutes $\geq 2296$ counts $/ \mathrm{min}$ from all valid days. Daily step count was calculated as the mean daily step count from all valid days. ActiGraph data was analysed using dedicated Actilife V.6.0 software (ActiGraph LLC, Pensacola, Florida, USA).

\section{Procedure}

Following agreement to participate in the study, participants were examined (initial measurements) and received an accelerometer for 7 days. After 7 days, the PAQ-A was delivered to students in their classroom during school time. Adolescents were asked to complete the questionnaire at home. Participants completed the PAQ-A again 1 week after completing the first questionnaire to assess test-retest reliability.

\section{Statistical analysis}

Descriptive statistics ( $\mathrm{n}$, frequencies $(\%)$, mean $\pm \mathrm{SD}$ ) were calculated for applicable variables. Test-retest reliability was assessed by one-way random-effects intraclass correlation coefficient (ICC).$^{30}$ Values of ICC less than 0.5 are indicative of poor reliability; between 0.5 and 0.75 indicate moderate reliability; between 0.75 and 0.9 indicate good reliability and greater than 0.90 indicate excellent reliability. ${ }^{31}$ The internal consistency of the questionnaire was analysed using Cronbach's $\alpha$ coefficient. Removing every item to confirm or exclude redundancy of the individual items was also performed by Cronbach's $\alpha$. Values of $\alpha$ greater than 0.7 were deemed acceptable for general research purposes. ${ }^{32}$ Additionally, item-total correlation values were calculated. Values for item-total correlation greater than or equal to 0.3 are considered as acceptable. ${ }^{33}$ Validity was assessed by calculating the relationship between PAQ-A scores and accelerometry-derived PA metrics using Spearman's rank correlation coefficients $(r)$. Values from 0.1 to 0.2 indicate poor correlation; from 0.3 to 0.5 fair; from 0.6 to 0.7 moderate and $\geq 0.8$ very strong correlation. ${ }^{34}$ Statistical significance was established as a p value less than 0.05 . All analyses were carried out using GNU R Software.

\section{RESULTS}

In total, 78 adolescents provided valid data for the PAQ-A and accelerometer measurements. The mean age of the participants was $15.7 \pm 1.41$ years. The mean non-wear time recorded by the accelerometers was $477 \mathrm{~min}$ /day (minimum $326 \mathrm{~min}$; maximum $840 \mathrm{~min}$ ). The general characteristics of the participants are presented in table 1.

Table 2 presents the results that indicate excellent test-retest reliability for the PAQ-A $(\mathrm{ICC}=0.97)$. Similar relationships were found among girls and boys separately (ICC $=0.96$ and 0.97 , respectively). Regarding individual item analyses, the lowest value $(\mathrm{ICC}=0.86)$ was observed for item 5, which informs about evening activity. The obtained correlations presented in table 2 show statistical significance at the level of $\mathrm{p}<0.01$. 
Table 1 Sample characteristic

\begin{tabular}{|c|c|c|c|}
\hline Variables & $\begin{array}{l}\text { Total } \\
(\mathrm{n}=78)\end{array}$ & $\begin{array}{l}\text { Girls } \\
(n=38)\end{array}$ & $\begin{array}{l}\text { Boys } \\
(n=40)\end{array}$ \\
\hline Age $\left(\right.$ years) ${ }^{*}$ & $15.70 \pm 1.41$ & $15.34 \pm 1.30$ & $16.05 \pm 1.43$ \\
\hline \multicolumn{4}{|l|}{ Age (years)† } \\
\hline 14 & $12(15.4)$ & $8(10.3)$ & $4(5.1)$ \\
\hline 15 & $14(18.0)$ & $7(9.0)$ & $7(9.0)$ \\
\hline 16 & $16(20.5)$ & $9(11.5)$ & $7(9.0)$ \\
\hline 17 & $12(15.4)$ & $4(5.1)$. & $8(10.3)$ \\
\hline 18 & $11(14.1)$ & $3(3.8)$ & $8(10.3)$ \\
\hline 19 & $13(16.6)$ & $7(9.0)$ & $6(7.6)$ \\
\hline Body height $(\mathrm{cm})^{*}$ & $167.43 \pm 10.49$ & $162.24 \pm 7.44$ & $172.26 \pm 10.65$ \\
\hline Body weight $(\mathrm{kg})^{\star}$ & $60.49 \pm 13.09$ & $56.90 \pm 12.76$ & $63.90 \pm 12.63$ \\
\hline BMI percentile* & $56.66 \pm 28.84$ & $58.03 \pm 29.41$ & $55.38 \pm 28.60$ \\
\hline \multicolumn{4}{|l|}{ Body mass category $\dagger$} \\
\hline Underweight & $5(6.41)$ & $3(7.89)$ & $2(5.00)$ \\
\hline Healthy weight & $56(71.80)$ & $26(68.42)$ & $30(75.00)$ \\
\hline Overweight & $12(15.38)$ & $5(13.16)$ & $7(17.50)$ \\
\hline Obesity & $5(6.41)$ & $4(10.53)$ & $1(2.50)$ \\
\hline \multicolumn{4}{|l|}{$P A Q-A^{*}$} \\
\hline Q1. Spare-time activity: sports & $1.85 \pm 0.72$ & $1.78 \pm 0.72$ & $1.92 \pm 0.71$ \\
\hline Q2. Activity during physical education classes & $3.27 \pm 0.94$ & $3.03 \pm 0.85$ & $3.50 \pm 0.96$ \\
\hline Q3. Lunchtime activity & $2.59 \pm 1.02$ & $2.42 \pm 1.08$ & $2.75 \pm 0.95$ \\
\hline Q4. After-school activity & $3.03 \pm 1.01$ & $2.76 \pm 0.94$ & $3.28 \pm 1.01$ \\
\hline Q5. Evening activity & $2.95 \pm 1.16$ & $2.74 \pm 1.16$ & $3.15 \pm 1.14$ \\
\hline Q6. Weekend activity & $2.71 \pm 1.11$ & $2.55 \pm 1.13$ & $2.85 \pm 1.08$ \\
\hline Q7. Activity frequency during the last 7 days & $2.99 \pm 1.23$ & $2.82 \pm 1.27$ & $3.15 \pm 1.19$ \\
\hline Q8. Activity frequency during each day last week & $3.09 \pm 0.89$ & $2.89 \pm 0.87$ & $3.29 \pm 0.87$ \\
\hline PAQ-A total & $2.82 \pm 0.79$ & $2.64 \pm 0.80$ & $2.99 \pm 0.76$ \\
\hline \multicolumn{4}{|l|}{ Accelerometry ${ }^{*}$} \\
\hline MVPA (min/day) & $44.71 \pm 17.24$ & $39.86 \pm 15.63$ & $49.32 \pm 17.61$ \\
\hline Steps count per day & $6928 \pm 3064$ & $6184 \pm 2650$ & $7635 \pm 3289$ \\
\hline
\end{tabular}

Data are expressed as: ${ }^{*}$ mean \pm SD; $†$ ( $(\%)$.

BMI, body mass index; MVPA, moderate-to-vigorous physical activity; PAQ-A, Physical Activity Questionnaire for Adolescents; Q, question.

The internal consistency coefficients of the questionnaire are presented in table 3. The PAQ-A obtained an internal consistency of $\alpha=0.93$. Cronbach's $\alpha$ indicators for the questionnaire with individual questions removed also had values above 0.9 . Item-total correlation values were the lowest for the first and second questions $(0.43$ and 0.49 , respectively). All item-total correlation values exceeded the cut-off of 0.30 indicating each question was related to the overall questionnaire.

Table 4 presents correlation between PAQ-A and accelerometry. Overall, associations were stronger for the overall PAQ-A score than individual subitems. A higher correlation was observed between the PAQ-A total score and the number steps per day $(\mathrm{r}=0.94)$ than between PAQ-A total score and MVPA ( $r=0.81)$. The obtained
Spearman correlation coefficients show statistical significance at the level of $\mathrm{p}<0.01$.

\section{DISCUSSION}

We found no questionnaires evaluating PA validated for Polish adolescents in the literature. Therefore, the present study is at the forefront of obtaining evidence for the validity of the questionnaire developed by Kowalski et al. ${ }^{18}$ We present the first PAQ-A cultural adaptation and validation study among Polish adolescents aged 14-19years. In general, the results of the present study show excellent reliability of the PAQ-A and a very strong correlation of the PAQ-A to accelerometer measurements. Our validity 


\begin{tabular}{|c|c|c|c|}
\hline Variables & $\begin{array}{l}\text { Total } \\
(n=78)\end{array}$ & $\begin{array}{l}\text { Girls } \\
(n=38)\end{array}$ & $\begin{array}{l}\text { Boys } \\
(n=40)\end{array}$ \\
\hline PAQ-A total & 0.97 & 0.96 & 0.97 \\
\hline $\begin{array}{l}\text { Q1. Spare-time activity: } \\
\text { sports }\end{array}$ & 0.97 & 0.96 & 0.98 \\
\hline $\begin{array}{l}\text { Q2. Activity during physical } \\
\text { education classes }\end{array}$ & 0.87 & 0.83 & 0.88 \\
\hline Q3. Lunchtime activity & 0.91 & 0.92 & 0.89 \\
\hline Q4. After-school activity & 0.87 & 0.82 & 0.88 \\
\hline Q5. Evening activity & 0.86 & 0.84 & 0.88 \\
\hline Q6. Weekend activity & 0.91 & 0.89 & 0.92 \\
\hline $\begin{array}{l}\text { Q7. Activity frequency } \\
\text { during the last } 7 \text { days }\end{array}$ & 0.96 & 0.94 & 0.97 \\
\hline $\begin{array}{l}\text { Q8. Activity frequency } \\
\text { during each day last week }\end{array}$ & 0.98 & 0.97 & 0.99 \\
\hline
\end{tabular}

PAQ-A, Physical Activity Questionnaire for Adolescents; Q, question.

coefficients are higher than previously reported by other validation studies with adolescents. ${ }^{20} 3536$

In the present study, the ICC for individual items of the PAQ-A ranged from 0.86 to 0.97 which is strong evidence to support good and excellent reliability. ${ }^{31}$ Good ICC values were observed for items 2,4 and 5 (ICC $=0.87,0.87$ and 0.86 , respectively), and excellent ICC values were found for the others. For the final score of the PAQ-A, test-retest reliability showed ICC $=0.97$, which is strong evidence to support reliability of the PAQ-A in this target population. The reliability of the PAQ-A ranged from poor (ICC $=0.40$ ) among Vietnamese adolescents ${ }^{37}$ to good in other studies conducted in other countries with adolescents of different races. ${ }^{20} 3839$ Aggio et al observed

\begin{tabular}{|c|c|c|}
\hline Variables & $\begin{array}{l}\text { Cronbach's } \\
\text { coefficient, } \alpha\end{array}$ & $\begin{array}{l}\text { Correlation } \\
\text { (item-total) }\end{array}$ \\
\hline PAQ-A total & 0.93 & - \\
\hline \multicolumn{3}{|c|}{ Reliability with items (Q1-Q8) individually removed } \\
\hline Q1. Spare-time activity: sports & 0.93 & 0.43 \\
\hline $\begin{array}{l}\text { Q2. Activity during physical } \\
\text { education classes }\end{array}$ & 0.93 & 0.49 \\
\hline Q3. Lunchtime activity & 0.92 & 0.71 \\
\hline Q4. After-school activity & 0.92 & 0.74 \\
\hline Q5. Evening activity & 0.91 & 0.84 \\
\hline Q6. Weekend activity & 0.91 & 0.81 \\
\hline $\begin{array}{l}\text { Q7. Activity frequency during the } \\
\text { last } 7 \text { days }\end{array}$ & 0.91 & 0.85 \\
\hline $\begin{array}{l}\text { Q8. Activity frequency during } \\
\text { each day last week }\end{array}$ & 0.92 & 0.74 \\
\hline
\end{tabular}

PAQ-A, Physical Activity Questionnaire for Adolescents; Q, question.
Table 4 Spearman's rank correlation between PAQ-A and accelerometry

\begin{tabular}{|c|c|c|}
\hline Variables & $\begin{array}{l}\text { MVPA } \\
\text { (min/day) }\end{array}$ & Steps/day \\
\hline Q1. Spare-time activity: sports & 0.56 & 0.56 \\
\hline $\begin{array}{l}\text { Q2. Activity during physical } \\
\text { education classes }\end{array}$ & 0.46 & 0.52 \\
\hline Q3. Lunchtime activity & 0.58 & 0.67 \\
\hline Q4. After-school activity & 0.73 & 0.76 \\
\hline Q5. Evening activity & 0.70 & 0.83 \\
\hline Q6. Weekend activity & 0.65 & 0.83 \\
\hline $\begin{array}{l}\text { Q7. Activity frequency during the } \\
\text { last } 7 \text { days }\end{array}$ & 0.68 & 0.82 \\
\hline $\begin{array}{l}\text { Q8. Activity frequency during } \\
\text { each day last week }\end{array}$ & 0.60 & 0.74 \\
\hline PAQ-A total & 0.81 & 0.94 \\
\hline
\end{tabular}

MVPA, moderate-to-vigorous physical activity; PAQ-A, Physical Activity Questionnaire for Adolescents; Q, question.

that the modified PAQ-A score was stable over time among British adolescents $(\mathrm{ICC}=0.78),{ }^{39}$ which was comparable with original research, ${ }^{19}$ and subsequent reliability studies among Spanish adolescents (ICC $=0.71) .{ }^{35}$

An estimate of Cronbach's coefficient $\alpha$ greater than 0.70 is usually considered to be indicative of a reliable questionnaire. ${ }^{32}$ In our study, Cronbach's $\alpha$ coefficients showed excellent internal consistency $(\alpha=0.93)$, higher in comparison with the original, ${ }^{19}$ and other modified versions of the PAQ-A. ${ }^{20} 35{ }^{39}$ Item-total correlations were the lowest for questions on spare-time activity, activity during physical education classes and lunchtime, which are consistent with previous findings. ${ }^{20} 353940$ Janz et $a l$ reported that Cronbach's $\alpha$ for the PAQ-A ranged from 0.72 to 0.88 . Moreover, authors suggested that completing the questionnaire during the summer months did not reduce the standardised $\alpha$ for the PAQA. ${ }^{20}$ Among British adolescents, Cronbach's $\alpha$ coefficient for the modified PAQ-A score showed acceptable interitem reliability $(\alpha=0.72)$. Item-total correlations showed how well each item correlated with the composite of the remaining items; correlations ranged from $\alpha=0.24$ to 0.54 with all additional and modified questions exceeding $\alpha=0.300 .{ }^{39}$ Bervoets et al also showed an acceptable reliability of PAQ-A for Dutch adolescents. Of all 94 PAQ-A questionnaires completed by adolescents, Cronbach's $\alpha$ was $0.76 .^{40}$

The PAQ-A was compared with device-based measures of PA to determine the validity of the PAQ-A using triaxial accelerometry. Accelerometers monitor PA by recording the acceleration of human movement. Movement sensors, such as pedometers and accelerometers, are suggested as one of the best methods for evaluation of PA and validation of PA self-report instruments. ${ }^{41}$ The convergent validity of the PAQ-A was assessed by calculating the correlation between the PAQ-A total score and different 
PA measures determined by an accelerometer (MVPA and number of steps per day). Very strong correlations were observed between the PAQ-A total score and number of steps per day $(\mathrm{r}=0.94)$ and with MVPA $(\mathrm{r}=0.81)$. This correlation for MVPA was higher than that obtained in the study reported by Janz et al. $(\mathrm{r}=0.63) .{ }^{20}$ Our results do not concur with a validation study of the PAQ-A conducted on Spanish adolescents, which showed reasonable validity of the PAQ-A for adolescents aged from 12 to 17 years $(\mathrm{r}=0.39) .{ }^{35}$ A correlation with MVPA much lower than in our study, but significant, was reported in a Chinese population $(\mathrm{r}=0.33)$ of children aged from 8 to 13 years. ${ }^{36}$ These data confirm a line of evidence suggesting that PA questionnaires for adolescents correlate better with scores obtained from an accelerometer than PA questionnaires for younger children. ${ }^{17}$

The assessment of PA plays a significant role in understanding patterns and influences of behaviour, designing interventions and monitoring. To describe the level of PA, a standardised, reliable and valid tool is essential. Furthermore, in the paediatric population, it is important to use methods which are non-invasive, easy to use and time-saving. Until the development of movement sensors, such as pedometers or accelerometers, the assessment method for PA has been self-reported. The magnitude of correlation between PA recall questionnaires for youth and device-based PA measures is different for different questionnaires. Results from a systematic review of 57 studies that examined the correlation of questionnairederived PA measures with accelerometry-derived PA measures indicate that overall correlations for total PA range from $r=0.14$ to $r=0.58$. Of the reviewed studies, only one-third report correlations equal to or higher than $0.40 .{ }^{14}$

Among the available validated self-report measures of PA dedicated to youth, one of the most promising tools may be PAQ-A. ${ }^{9}$ The strength of the PAQ-A is that it is an easy-to-use, relatively inexpensive and a quickto-administer self-report tool. The PAQ-A also provides specific information about activity levels during different periods of the day (eg, recess, physical education, after school, etc.) as well as a general PA level for a whole week. However, questionnaire do not estimate precise amount, frequency, intensity and duration of PA, what is essential for example, in accurate examination of dose-response relationship between PA and health or evaluation of the effectiveness of PA-enhancing interventions. ${ }^{18}$ Both self-report and device-based measures of PA have its strengths and limitations, thus for measuring PA a combination of the device-based measures (such as accelerometers) and self-report questionnaires seems most promising. ${ }^{42}$

Excellent ICC and internal consistency, as well as very strong convergent validity with accelerometer-based measures have provided evidence that the PAQ-A can be a useful tool for large PA assessment studies with Polish adolescents.

\section{Limitations}

Potential limitations of this study need to be taken into account when interpreting the results. The PAQ-A is appropriate for high-school students between approximately 14 and 20 years of age who are currently in the school system. However, the age range of participants recruited in the current study was 14-19years. The difference in age range is due to the education system in Poland, in which students finish high school at the age of 19.

The relatively small sample size can also be considered as a limitation; however, the sample size was similar to the original validation study. ${ }^{19}$

Another limitation in our study is the missing of a sleeping diary, the relatively high dropout rate of participants due to accelerometer non-wear periods and a lack of data on their age, sex, BMI and PA level.

The fact that participants completed the PAQ-A at home can also be considered as a limitation of the study. However, researchers emphasised to participants that the questionnaire responses need to refer to the week they wore the accelerometer.

In our study, we did not adjust for differences in non-wear periods in the accelerometer measurements, because the measurement was carried out 24 hours/day. ${ }^{43}$

Some authors suggest that internal consistency is not relevant for PA questionnaires because items refer to different aspects of the construct, for example, duration versus frequency or sports versus work and these items do not need to be highly correlated. ${ }^{44}$ However, we decided to include these analyses, as it allows to compare our results with the results of other authors.

\section{CONCLUSION}

This is the first study addressing the validity and reliability of PAQ-A in Polish adolescents which may help to assess the applicability of the questionnaire. Our results show that the Polish version of PAQ-A provides reliable and valid estimates of PA among adolescents aged 14-19 years. The Polish version of PAQ-A can be considered as very useful in clinical practice and epidemiological studies to assess overall levels of PA in adolescents.

Acknowledgements We are grateful to the participants and their families who volunteered their time to participate in this research.

Contributors JW-development of the concept of research. JW, JP-B, KD, JB, $\mathrm{PM}, \mathrm{JH}$-data compilation. KP, AM, JW, PM-analysis and interpretation of data. KP-statistical analysis. JW-writing the manuscript. JP-B, JB, KD-substantive review article. AM, PM-overseeing the final article. All authors read and approved the final version of the manuscript.

Funding The authors have not declared a specific grant for this research from any funding agency in the public, commercial or not-for-profit sectors.

Competing interests None declared.

Patient consent for publication Not required.

Ethics approval The study was conducted in accordance with the ethical rules of the Helsinki Declaration. The study protocol was approved by the Bioethics Committee of the University of Rzeszów (Poland), approval number 9/05/2012

Provenance and peer review Not commissioned; externally peer reviewed. 
Data availability statement Data are available upon reasonable request.

Open access This is an open access article distributed in accordance with the Creative Commons Attribution Non Commercial (CC BY-NC 4.0) license, which permits others to distribute, remix, adapt, build upon this work non-commercially, and license their derivative works on different terms, provided the original work is properly cited, appropriate credit is given, any changes made indicated, and the use is non-commercial. See: http://creativecommons.org/licenses/by-nc/4.0/.

ORCID iDs

Justyna Wyszyńska http://orcid.org/0000-0002-5786-6214

Krzysztof Przednowek http://orcid.org/0000-0002-2128-4116

\section{REFERENCES}

1 Caspersen CJ, Powell KE, Christenson GM. Physical activity, exercise, and physical fitness: definitions and distinctions for healthrelated research. Public Health Rep 1985;100:126-31.

2 Lee I-M, Shiroma EJ, Lobelo F, et al. Effect of physical inactivity on major non-communicable diseases worldwide: an analysis of burden of disease and life expectancy. Lancet 2012;380:219-29.

3 World Health Organization. Prevalence of insufficient physical activity. Available: http://www.who.int/gho/ncd/risk_factors/physical_activity/ en/ [Accessed 9 Jul 2019].

$4 \mathrm{Ng} \mathrm{M}$, Fleming T, Robinson M, et al. Global, regional, and national prevalence of overweight and obesity in children and adults during 1980-2013: a systematic analysis for the global burden of disease study 2013. Lancet 2014;9945:766-81.

5 World Health Organization. Obesity and overweight. Available: https://www.who.int/news-room/fact-sheets/detail/obesity-andoverweight [Accessed 9 Jul 2019].

6 Daniels SR, Jacobson MS, McCrindle BW, et al. American Heart Association Childhood Obesity Research Summit. Circulation 2009;119:2114-23.

7 Donnelly JE, Hillman CH, Castelli D, et al. Physical activity, fitness, cognitive function, and academic achievement in children. Med Sci Sports Exerc 2016;48:1197-222.

8 Sylvia LG, Bernstein EE, Hubbard JL, et al. Practical guide to measuring physical activity. J Acad Nutr Diet 2014;114:199-208.

9 Biddle SJH, Gorely T, Pearson N, et al. An assessment of selfreported physical activity instruments in young people for population surveillance: Project ALPHA. Int J Behav Nutr Phys Act 2011;8.

10 Sallis JF, Saelens BE. Assessment of physical activity by selfreport: status, limitations, and future directions. Res $Q$ Exerc Sport 2000;71:1-14.

11 Westerterp KR. Assessment of physical activity: a critical appraisal. Eur J Appl Physiol 2009;105:823-8.

12 Pate RR, Almeida MJ, Mclver KL, et al. Validation and calibration of an accelerometer in preschool children. Obesity 2006;14:2000-6.

13 Sallis JF. Measuring physical activity: practical approaches for program evaluation in native American communities. $J$ Public Health Manag Pract 2010;16:404-10.

14 Skender S, Ose J, Chang-Claude J, et al. Accelerometry and physical activity questionnaires - a systematic review. BMC Public Health 2016;16:515.

15 Helmerhorst HJF, Brage S, Warren J, et al. A systematic review of reliability and objective criterion-related validity of physical activity questionnaires. Int J Behav Nutr Phys Act 2012;9.

16 van Poppel MN, Chinapaw MJ, Mokkink LB, et al. Physical activity questionnaires for adults: a systematic review of measurement properties. Sports Med 2010;40:565-600.

17 Chinapaw MJM, Mokkink LB vanP, et al. Physical Activity Questionnaires for youth. A systematic review of measurement properties. Sports Med 2010;40:539-63.

18 Kowalski KC, Crocker PRE, Donen RM. The Physical Activity Questionnaire for Older Children (PAQ-C) and Adolescents (PAQ-A) Manual. Canada: College of Kinesiology, University of Saskatchewan, 2004: 1-38.

19 Kowalski KC, Crocker PRE, Kowalski NP. Convergent validity of the Physical Activity Questionnaire for Adolescents. Pediatr Exerc Sci 1997;9:342-52.
20 Janz KF, Lutuchy EM, Wenthe P, et al. Measuring activity in children and adolescents using self-report. Med Sci Sports Exerc 2008;40:767-72.

21 Geisinger KF. Cross-cultural normative assessment: translation and adaptation issues influencing the normative interpretation of assessment instruments. Psychol Assess 1994;6:304-12.

22 Kułaga Z, Różdżyńska A, Palczewska I. Percentile charts of height, body mass and body mass index in children and adolescents in Poland - results of the OLAF study. Stand Med 2010;7:690-700.

23 Barlow SE, Committee E. Expert committee recommendations regarding the prevention, assessment, and treatment of child and adolescent overweight and obesity: summary report. Pediatrics 2007;120:S164-92.

24 Lee I-M, Shiroma EJ. Using accelerometers to measure physical activity in large-scale epidemiological studies: issues and challenges. Br J Sports Med 2014;48:197-201.

25 Sasaki JE, John D, Freedson PS. Validation and comparison of ActiGraph activity monitors. J Sci Med Sport 2011;14:411-6.

26 Santos-Lozano A, Santín-Medeiros F, Cardon G, et al. Actigraph GT3X: validation and determination of physical activity intensity cut points. Int J Sports Med 2013;34:975-82.

27 Puyau MR, Adolph AL, Vohra FA, et al. Validation and calibration of physical activity monitors in children. Obes Res 2002;10:150-7.

28 Troiano RP, Berrigan D, Dodd KW, et al. Physical activity in the United States measured by accelerometer. Med Sci Sports Exerc 2008;40:181-8.

29 Evenson KR, Catellier DJ, Gill K, et al. Calibration of two objective measures of physical activity for children. J Sports Sci 2008;26:1557-65.

30 Bartko JJ. The intraclass correlation coefficient as a measure of reliability. Psychol Rep 1966;19:3-11.

31 Koo TK, Li MY. A guideline of selecting and reporting intraclass correlation coefficients for reliability research. J Chiropr Med 2016;15:155-63.

32 Cronbach LJ. Coefficient alpha and the internal structure of tests. Psychometrika 1951;16:297-334.

33 Nunnally J, Bernstein I. Psychometric theory. New York: McGrawHill, 1994.

34 Chan YH. Biostatistics 104: correlational analysis. Singap Med J 2003:44:614-9.

35 Martinez-Gomez D, Martinez-de-Haro V, Pozo T, et al. Reliability and validity of the PAQ-A questionnaire to assess physical activity in Spanish adolescents. Rev Esp Salud Publica 2009;83:427-39.

36 Wang JJ, Baranowski T, Lau WP, et al. Validation of the physical activity questionnaire for older children (PAQ-C) among Chinese children. Biomed Environ Sci 2016;29:177-86.

37 Lachat CK, Khanh L, Khanh L, et al. Validity of two physical activity questionnaires (IPAQ and PAQA) for Vietnamese adolescents in rural and urban areas. Int J Behav Nutr Phys Act 2008;5.

38 Voss C, Dean PH, Gardner RF, et al. Validity and reliability of the Physical Activity Questionnaire for Children (PAQ-C) and Adolescents (PAQ-A) in individuals with congenital heart disease. PLoS One 2017;12:e0175806.

39 Aggio D, Fairclough S, Knowles Z, et al. Validity and reliability of a modified English version of the physical activity questionnaire for adolescents. Arch Public Health 2016;74:3.

40 Bervoets L, Van Noten C, Van Roosbroeck S, et al. Reliability and validity of the Dutch Physical Activity Questionnaires for Children (PAQ-C) and Adolescents (PAQ-A). Arch Public Health 2014;72:47.

41 Vanhelst J, Hardy L, Gottrand F, et al. [Technical aspects and relevance of physical activity assessment in children and adolescents in free-living conditions]. Arch Pediatr 2012;19:1219-25.

42 Hidding LM, Chinapaw MJM, van Poppel MNM, et al. An updated systematic review of childhood physical activity questionnaires. Sports Med 2018;48:2797-842.

43 Herrmann SD, Barreira TV, Kang M, et al. How many hours are enough? Accelerometer wear time may provide bias in daily activity estimates. J Phys Act Health 2013;10:742-9.

44 Terwee CB, Mokkink LB, van Poppel MNM, et al. Qualitative attributes and measurement properties of physical activity questionnaires. Sports Med 2010;40:525-37. 